\title{
Understanding Collaborations between Chinese and the U.S. Universities: The Development of a Typology
}

\author{
Hui Kang ${ }^{1}$, a, Genshu Lu², Linda Serra Hagedorn ${ }^{3}$ \\ ${ }^{1}$ Xi'an Aeronautical Polytechnic Institute, Xi'an, 710089 China \\ ${ }^{2}$ Xi'an Jiaotong University, Xi'an, 710049 China \\ ${ }^{3}$ School of Education, lowa State University, Ames, IA 50011 USA \\ ahelenkh@126.com
}

Keywords: Collaboration, Universities, Typology.

\begin{abstract}
There has been a recent and rapid increase in the number and forms of educational collaborations between the U.S. and China in recent decades. Through the years these collaborations have evolved from the simplest forms of welcome of international students and faculty to complex agreements and even new postsecondary institutions. In this manuscript, we develop a typology to better understand the various varieties of educational collaborations using examples of the various forms between universities in the U.S. and China.
\end{abstract}

\section{Introduction}

As co-chairs of the China-US consultation on People-to-People Exchange (CPE), Chinese Vice-Premier Liu Yandong and U.S. Secretary of State John Kerry, recently agreed that a higher level of collaboration between universities in China and the U.S. would bring benefits to both countries [1]. Indeed, collaboration between these two powerful and influential countries is rapidly increasing. According to The Economist [2], more western universities are interested in collaborating with Chinese institutions but may encounter significant difficulties due to the great differences between the two countries and their educational systems. In this manuscript, we develop a typology to better understand the various varieties of educational collaborations using examples of collaborations specifically between the U.S. and China.

During the last three decades Sino-U.S. collaborations have grown and developed greatly. Collaboration is no longer limited to establishing one-way student study abroad, but also to new institutes and even to the construction of entire universities. Contemporary university collaborations may include exchange of students and/or faculty as well as to establishing programs of research. Moreover, the players are no longer limited to individuals solely associated with the universities themselves, but extend also to the governments, academic associations, non-governmental organizations and others. The level of collaboration often includes both the undergraduate and graduate levels.

\section{Definition of Collaboration and Cooperation}

The words "collaboration" and "cooperation" have often mistakenly been used interchangeably. Some scholars have explained the relationship between the terms citing that collaboration can only emerge as a result of the prior establishment of cooperation [3, 4]. Other scholars point to collaboration as more inclusive and more likely to lead to improved outcomes [5]. According to the New England Program in Teacher Education [6], the definition of collaboration is the development of a model of joint planning, joint implementation, and joint evaluation between individuals or organizations. Cooperation, on the other hand, does not progress beyond the level of reaching mutual agreement. Therefore, from the aforementioned definitions it may be concluded that collaboration is 
not possible without cooperation and may only occur after a high level of cooperation is present producing opportunities and promoting a deepening of the cooperative relationship.

\section{The Outputs of Collaboration}

We propose that the current forms of collaborations can be divided into four types; education collaboration programs, risen universities/colleges, language and culture centers, and lesser collaborative forms including international conferences, visits, reports, seminars and others products.

\subsection{Education Programs}

The term "program" can have various definitions. For the purposes herein we have divided education programs into degree and non-degree. Degree programs consist of courses, experiences, and activities leading to a degree in a specific major or discipline. Non-degree programs involve focused activities typically resulting in cultural exchange, mutual understanding, and global awareness without degrees conferred. Another level of the program involves time or duration; dichotomized here as long-term or short-term. Programs involving participants for less than an academic semester may be defined as short-term while those requiring participation for one academic semester or longer are described as long-term. Degree programs are almost always long-term due to the time requirements for students to earn degrees. Non-degree programs can be either long-term or short term. For example, international summer schools or camps are non-degree programs often operated during summer or winter vacations lasting for a few weeks. Some graduate programs sponsored by CSC to support students at Chinese universities to visit foreign universities for one to two years without pursuing degrees are long-term non-degree programs. Figure 1 presents a schematic of the program types collaborated between Chinese and the U.S. universities.

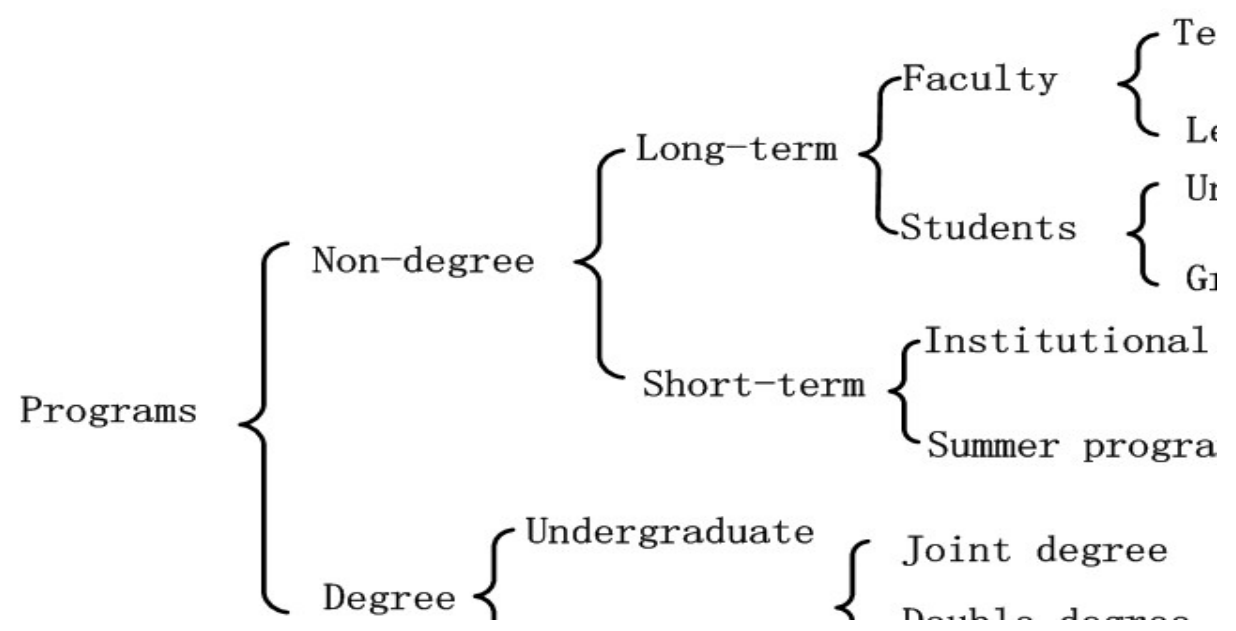

Figure 1. The programs collaborated between Chinese and the U.S. universities

\subsection{Degree Programs}

There are several types of degree programs which can be classified as dual degree, joint degree or single degree and can be at either the undergraduate or the graduate level.

Dual degree programs, sometimes referred to as double degree, are programs where both universities confer a degree after students meet the requirements of both the Chinese and the U.S. universities. An example of a dual degree program can be seen through the collaboration between Shanghai Jiaotong University (SJTU) and Georgia Instiute of Technology (GIT). This program, offered to Shanghai Jiaotong University master degree students in Electronic and Computer Engineering or Industry and System Engineering results in the conferring of degrees by both SJTU and GIT. SJTU also has established dual master degree programs with California Polytechnic State University in agriculture and biology, and dual doctoral degree programs with Michigan State University, Georgia Institute of Technology and the University of Nebraska [7].

Collaborated dual degree programs are frequently described by the expected number of years spent at each institution to earn the degree; two plus three $(2+3)$, three plus two $(3+2)$, two plus two $(2+2)$, 
and other forms are included in this category. Another variation of the dual degree program includes programs that are designed to earn a degree from both universities but at different levels such as a bachelor degree from the university in one country and a master degree from the university in the other country. For instance, the Tsinghua University (UIUC3+2) program collaborates with the University of Illinois at Urbana-Champaign (UIUC) in several disciplines including Chemical Engineering, Bio-molecular Engineering, Civil Engineering, Mechanical Engineering, Environment Engineering, Bioengineering, Accounting, and Human Resource Management. Third year students at Tsinghua University are selected to participate in the program and continue their study in UIUC for two years. After meeting the requirements of the program, Tsinghua University confers the Bachelor Degree and UIUC confers the Master Degree [8]. Collaborated universities create their own programs by negotiation. Therefore, these programs vary greatly in forms.

\subsubsection{Joint Degree Collaborations}

Hagedorn and $\mathrm{Hu}$ [9] defined joint degrees as two institutions (one American and the other Chinese) collaborating on the awarding of a single degree. The resulting diploma typically records both institutions. Due to the necessity of deep collaboration, agreement, and individualization, true joint degrees are rare. We offer the example of the joint degree program between Peking University and Georgia Technical University. This joint degree program was established in 2010 to cultivate Doctoral students in bio-medical and material disciplines. Students spend most of their time in Beijing and then go to Georgia Technical University for some research work and students are registered at both universities. After graduation, they are conferred degrees jointly by two universities [10]. This joint degree program represents the first agreement to allow two universities to put their stamps on one degree that has been approved by the Chinese National Committee for Academic Degrees [11].

\subsubsection{Single Degree Programs}

Hagedorn and $\mathrm{Hu}$ [9] stated that in single degree programs "Students will take courses in one country and transfer into the other earning the degree from the second institution" (34-46). This type of collaboration generally includes agreement on how students are admitted as well as the articulation of transfer credits. A collaborated single degree is negotiated between the Chinese and the U.S. universities and generally includes a signed agreement or contract. An example of a negotiated single degree program involves Chongqing University and the University of Missouri Columbia. Students who finish their first two years' study in Chongqing University can apply to continue their study at the University of Missouri Columbia. After credits are transferred and the students complete the corresponding requirements, students are awarded the bachelor degree by the University of Missouri Columbia. Another example is the negotiated collaboration between Henan Normal University and Iowa State University (ISU). After earning a bachelor degree at Henan Normal University (HNNU), students add two graduate courses and transfer the credits into the Global Leadership master degree at ISU. Students earn the master degree in Global Leadership singularly conferred by ISU.

\subsubsection{Summary of Degree Programs}

This manuscript has provided a framework that differentiates dual degree, joint degree, and single degree programs. In summary, students enrolled in dual degree programs earn two distinct degrees. Students enrolled in joint degree programs earn a single degree jointly conferred by both Chinese and U.S. universities. Finally, students enrolled in single collaborated degree programs enroll in the program in one country with the goal of transferring the credits toward the single degree in the other country.

\subsection{Non-Degree Programs}

Similar to the degree granting program, we divide non-degree programs into short and long-term programs. Short-term programs include summer schools, summer camp, spring break programs and others designed to provide a brief experience lasting for several days to several weeks. Chinese and U.S. universities collaborate through signed agreements or as part of established partnerships to send students or other affiliates abroad for these experiences. The short-term programs often provide the opportunities for cultural communication, academic exchange, and international experience. Some 
programs may allow student to take a limited number of courses with the possibility of credit transfer to the home university.

Long-term non-degree programs often range from six months to two years. On the China side, these programs are often sponsored and subsidized by the Chinese Scholarship Council. These programs serve undergraduates, graduates and faculty mainly from the " 985 " and " 211 " universities. In May 1998, President Jiang Zemin, proposed the 985 projects to establish world class universities in China. The project derives its name first from the nine original universities and the current 39-member universities [12]. In the 1990s, Project 211 was proposed with the goal of developing 100 key universities or disciplines in the $21^{\text {st }}$ century [13].

On the U.S. side, the Fulbright program provides many groups including teachers, students, professionals, researchers and so forth from different fields with non-degree programs to fully or partially support their study, research and teach. These different sub-programs under the Fulbright program serve both citizens and non-citizens, proving them the opportunities to exchange.

\subsection{Risen Universities}

Perhaps the ultimate example of collaborations results in the establishment of an entire new university or college. These new institutions, hereafter referred to as "risen universities" may take the form of a branch campus, satellite, or a new independent institution. All risen institutions have historical roots connected to the original collaboration.

Jane Knight [14] defines a branch campus as "a provider in Country A establishes a satellite campus in Country B to deliver courses and programs to students in Country B (Country A students may also take a semester or courses abroad). The qualification awarded is from the provider in Country A." Knight also proposed the definition of the independent institution as a "stand-alone higher education institution established in country B independently by a traditional university, a commercial company or alliance" with the absence of a "home institution" in country A [14]. While risen universities may maintain an affiliation with the original institutions, they become independent and maintain independent campus and administration organization. In accordance with the Regulations of the People's Republic of China on Chinese-Foreign Cooperation in Running Schools [15] enacted by the State Council of the People's Republic of China, risen universities are defined as the Institutes of Chinese-Foreign Cooperation in Running Schools (CFCRS).

Although admission to most of the risen universities requires the Chinese national college entrance exam (Gaokao) or the national postgraduate entrance exam for admission, they have more autonomy and are more flexible in teaching and learning compared to Chinese traditional universities. Reasons why the risen universities have been welcomed to China include that they are seen as a tool for the internationalization of the country's higher education network, may attract educational resources, and by supplying a predominantly Western type of education, may prevent some of the brain drain.

According to the information released by the Chinese Ministry of Education in February, 2014, there are forty-five risen universities/colleges as a result of collaboration by Chinese and international universities. To date there are eight risen universities resulting from collaboration with the U.S.:

Zhuoyue International University collaborated between University of International Business and Economics from China and Fort Hays State University from the United States,

Shanghai Jiaotong Michigan Joint Institute collaborated between Shanghai Jiaotong University and University of Michigan,

Shanghai New York University collaborated between East China University and New York University,

Duke Kunshan University collaborated between Duke University and Wuhan University, will recruit the first group of students in the fall of 2014,

SYSU-CMU Shunde International Joint Research Institute collaborated by Sun Yat-sen University and Carnegie Mellon University,

Sias International University collaborated between Zhengzhou University and Fort Hays State University, 
LNU-MSU College of International Business collaborated by Liaoning Normal University and Missouri State University,

College of International Business, Shenyang Normal University collaborated by Shenyang Normal University and Fort Hays State University,

In addition, there are two risen universities developed as a result of three-way collaborations by the U.S., Canada and China including Jiangnan University-North American College and Jilin University-Lambton College.

\subsection{Language and Cultural Centers}

Language and cultural centers are important forms of collaboration between Chinese and the U.S. Universities. As of this writing there are 19 American Cultural Centers for cultural exchange (ACCs) (Squarespace, n.d.), funded by the U.S. Department of State. The ACCs are physical locations on Chinese campuses with the charge of developing a deeper cultural understanding between the two nations. Although there is variation among the ACCs, most contain a library of American books and movies, promote advanced English language learning, and sponsor cultural events such as concerts, plays, and debates. In conjunction with their American partner institution, ACCs may sponsor initiatives such as summer camps, conferences, and lectures to promote mutual communication and exchange (Squarespace, n.d.). For example, the Henan Normal- American Cultural Center was established in 2012 and collaborated by Henan Normal University and Iowa State University. Through the partnership of two universities, activities such as summer camp, campus visits, inviting professors and artist for lectures and performances, and the hosting of e-conferences to promote the understanding and communication. Meanwhile, by these informal communication activities, further academic exchanges are also accelerated [16].

Confucius institutes are non-profit institutions established in 2004 by National Hanban (a sub-affiliate under the Ministry of Education) which engages in providing resources and service of teaching and learning in Chinese language and culture. Confucius institutes are the major forms of promoting Chinese language and culture exchange between China other countries. By collaboration with foreign universities and some other educational institutes, Confucius institutes teach Chinese language, cultivate Chinese teachers and sponsor cultural exchange activities. They have become a platform for cultural exchanges between China and the world as well as a bridge reinforcing friendship and cooperation between China and the rest of the world. Collaborated with universities and some other institutes in the U.S., ninety-seven Confucius institutes have been established as of 2013[17]. Some activities like summer camp, forums and seminars, and annual Chinese Language Bridge Cup Contest are jointly sponsored by both the Chinese and the U.S. sides in Confucius institutes.

\section{Summary}

As the relationship between China and the US has developed, a culture of collaboration and exchange has become more frequent and has taken several forms. We have proposed terminology and typography to assist in understanding the collaborations and their outcomes. However, we must clearly point-out that the outcomes of collaboration are far from being evenly distributed. Virtually all of the degree programs consist of Chinese students coming to the U.S. to study. Despite strong institutional collaborations, there are no long-term major programs sending Americans to China to earn a degree. The "lop-sided" results are due to many factors including American disinterest in learning the Chinese language and to beliefs in the superiority of the American higher education enterprise. Moreover, all risen universities have been established in China and none in the U.S. Thus, despite the terms and definitions, we can't help but wonder if collaboration, a term clearly indicating mutual involvement and bilateral interaction is currently the appropriate term. The true test of collaboration will be if the future will bring American interests to study in China or to establish a risen university in the U.S. 


\section{Acknowledgements}

This study is finally supported by the Shaanxi Province Social Science Fund (NO: 2017P013) and the Shaanxi Province Vocational Education Research Fund (NO: SZJZ-1702)

\section{References}

[1]. Quacquarelli Symonds Limited. 2013, Universities in China and the US to Step UpCollaboration.http://www.topuniversities.com/student-info/university-news023/universitieschina-us-step-collaboration.

[2]. The Economist. (2013) "Campus Collaboration". The Economist, Jan 5. http://www.economist.com/news/china/21569070-foreign-universities-find-working-china-hard er-they-expected-campus-collaboration.

[3]. Kostka J, Hall S, Moran P, Harris J (1994) Collaborative teams: bridges for clinical and management practice. Nursing Administration Quarterly Summer: 22-28

[4]. Pitillo R, Ross FM (1998) Policies for inter-professional education: current trends in the UK. Education for Health 11(3): 285-295

[5]. Walls G (1996) Cooperation as a distinctive practice, Social Development Issues 18(1): 1-14

[6]. New England Program in Teacher Education, (1973) The first five years' activities under public act 761 and public act 230-Review and Recommendations-A Report in Teacher Education, Inc., 115,581

[7]. Shanghai Jiaotong University (2008) International communication and cooperation: Overview. http://www.gs.sjtu.edu.cn/ic/news/showGeneral.ahtml

[8]. Tsinghua University (2007) Introduction of the (UIUC3+2) program. http://gjcbg.cic.tsinghua.edu.cn/gjc_out/detail.jsp?seq=3986\&boardid=970410

[9]. Hagedorn, L.S., \& Hu. J. (2014). Non-traditional Paths: New International Student Pathways to the Baccalaureate. Strategic Enrollment Management, 2(1), 34-46.

[10]. Peking University Gazette. (2010) Collaboration with Georgia Technical University in joint cultivating Ph.D. Student. Peking University Gazette, May 5, A2

[11]. Yang Xinyu (2008) Introduction: A view from China, U.S.-China Educational Exchange: Perspectives on a Growing Partnership. Institute of International Education, New York.

[12]. The Central People's Government of People's Republic of China (2008) “985" Project University. http://www.gov.cn/fwxx/2009gk/content_1314252.htm

[13]. Xinhuanet (n.d.) “211” Project http://news.xinhuanet.com/ziliao/2005-01/19/con Tent 2479728.htm

[14]. Jane Knight, (2006) Higher Education Crossing Borders: A Guide to the Implications of the General Agreement on Trade in Services (GATS) for Cross-border Education, COL/UNESCO, p20-21

[15]. State council, (2003) Regulations of the People's Republic of China on Chinese-Foreign Cooperation in Running Schools. State council

[16]. Henan Normal University (2013) Overview of College of International Education. http://www.henannu.edu.cn/gjjl/

[17]. Hanban. (2014) About Confucius Institute/Classroom. http://english.hanban.org /node_10971.htm 